\title{
PENGEMBANGAN SISTEM DATA AKUISISI DAN PEMANTAUAN BERGERAK FAKTOR PEMBANGKITAN PANEL SURYA PADA SUATU DAERAH TERPENCIL
}

\section{On The Development Of Photovoltaic Panel Generation Factor Data Acquisition And Mobile Monitoring On A Remote Area}

\author{
Hery Teguh Setiawan ${ }^{[1]}$, Dwi Novianto ${ }^{[1]}$, Risky Via Yuliantari ${ }^{[1]}$, Warindi ${ }^{[2]^{*}}$ \\ ${ }^{[1]}$ Teknik Elektro, Universitas Tidar \\ Jl. Kapten Suparman 39 Magelang, INDONESIA \\ ${ }^{[2]}$ Teknik Elektro, Universitas Mataram \\ JI. Majapahit 62, Mataram, INDONESIA \\ ${ }^{*}$ Corresponding author: warindi@unram.ac.id
}

\begin{abstract}
ABSTRAK
Energi surya merupakan sumber energi terbarukan yang berpotensi besar untuk dikembangkan di Indonesia. Namun selama ini pemanfaatan energi surya tersebut masih bersifat sektoral dan belum terencana secara efektif dan efisien. Untuk merencanakan suatu sistem pembangkit tenaga surya perlu diketahui factor pembangkitan panel atau Panel Generation Factor (PGF) yang mencerminkan potensi energi surya yang spesifik tergantung kondisi geografis suatu daerah. Penentuan PGF dapat dilakukan secara analitik atau eksperimental. Pengukuran eksperimental memberikan data yang lebih akurat tentang nilai PGF suatu daerah tetapi membutuhkan waktu dan sumber daya yang lebih besar dalam implementasinya. Penelitian ini bertujuan untuk mengetahui nilai PGF spesifik di suatu wilayah secara eksperimental, yaitu dengan menggunakan sistem data akuisisi dan pengamatan bergerak (mobile) jarak jauh. Hasil penelitian menunjukkan nilai analitik dan eksperimental PGF masing-masing sebesar 3,171 dan 3,1971. Penyimpangan antara hasil eksperimen dan analitis adalah 0,81\%. Hal ini menunjukkan bahwa sistem pemantauan bergerak jarak jauh dan data akuisisi yang diaplikasikan dapat mengukur PGF di suatu wilayah tertentu dengan baik.
\end{abstract}

Kata kunci: energi surya, panel generation factor, data akuisisi, pemantauan bergerak

ABSTRACT

Solar energy is a potential source that can be developed in Indonesia. The use of solar energy is still sectoral. It has not been planned effectively and efficiently. Ideally, a solar power plant does need to calculate Panel Generation Factor (PGF). PGF measurement can be done analytically or experimentally. Experimental measurements provide accurate data on the PGF value of an area but require times and resources for implementation. So, this research was conducted to determine the value of specific PGF in an area experimentally using data acquisition and a mobile remote monitoring system. The results show the analytical and experimental value of PGF was 3,171 and 3,1971. The deviation between the experimental and analytical results was $0.81 \%$. These results show that the monitoring and data acquisition system has been worked correctly for the PGF measurement in the specific area.

Key words: solar energy, panel generation factor, data acquisition, mobile monitoring

\section{PENDAHULUAN}

Energi listrik merupakan salah satu kebutuhan masyarakat modern yang sangat penting dan vital. Penyangga utama kebutuhan energi listrik di indonesi selama ini masih mengandalkan energi fosil yang terbatas dan tidak ramah lingkungan. Sebagian besar kebutuhan energi di Indonesia dihasilkan dari sumber energi fosil. Pada tahun 2025 pemerintah Indonesia bertekad untuk mengurangi penggunaan sumber energi fosil. Penggunaan sumber energi terbaharukan diharapkan mencapai $23 \%$ dari total produksi energi nasional[1]. Energi surya merupakan sumber energi terbaharukan yang potensial untuk dikembangkan di Indonesia. Penerapan energi surya telah bayak dilakukan di Indonesia tidak hanaya sebagai sumber energi rumah tangga, namun banyak juga penerapan lainnya diantaranya untuk lampu penerangan jalan[2], pengering pupuk 
otomatis[3], sistem penerangan darurat[4], dan sumber energi untuk filtrasi air[5].

Perencanaan aplikasi solar panel di Indonesia pada umumnya belum dirancang secara detail dan optimal, karena pada proses perancangan terdapat beberapa variable yang belum diikutkan dalam proses perancangan. Untuk merancang sistem pembangkit tenaga surya secara optimal maka Derating Factor (DF), serta Panel Generation Factor (PGF) merupakan variable yang mutlak harus diperhitungkan selain beberapa variable lainnya seperti yang terdapat pada [6].

Derating Factor merupakan faktor penghambat sebuah panel surya mencapai maksimal daya yang dibangkitkan sesuai dengan yang tertera pada nameplate sedangkan PGF merupakan hasil perkalian dari total radiasi horizontal yang diterima oleh Photovoltaik(PV) terhadap DF[7]. PGF dapat diketahui secara eksperimental maupun dengan menggunakan bantuan software. Perhitungan PGF telah dilakukan pada [8], [9] dengan mengukur arus dan tegangan yang dihasilkan oleh PV secara manual selama rentang waktu tertentu dalam satu hari, sehingga diperoleh total energi yang dihasilkan oleh panel dalam jangka satu hari tersebut. Pengukuran secara manual dalam rentang yang cukup lama, serta dengan titik pengukuran yang berbeda memiliki konsekuensi terhadap biaya dan sumberdaya yang harus dikeluarkan. Pengembangan sistem data akuisisi bergerak (Mobile Station) dapat mempermudah serta mengurangi biaya dan sumberdaya dalam pengukuran PGF dalam rangka penerapan sistem pembangkit energi surya di lapangan.

\section{METODOLOGI}

\section{a. Sistem Data Akuisisi Dan Pemantauan Bergerak}

Pada penelitian ini arus dan tegangan yang dihasilkan oleh solar panel diukur dan dikirim dalam rentang 1 jam selama 45 menit. Tegangan diukur menggunakan sensor modul dan sensor tegangan dengan rentang pengukuran $0-25 \mathrm{~V}$, sedangkan sensor arus menggunakan acs712-50 dengan rentang pengukuran hingga $50 \mathrm{~A}$. hasil pembacaan tegangan dan arus selanjutnya dibaca oleh Arduino uno melalui PIN analog $\mathrm{AO}$ dan PIN analog $A 1$, dengan menggunakan modul GSM SIM800L selanjutnya data hasil pembacaan dikirim secara simultan dengan selang waktu selama 1 jam. rentang waktu 1 jam dihitung maju menggunakan fungsi millis yang terdapat pada Arduino IDE, sedangkan pengambilan data dilaksanakan selama 3 hari berturut-turut. Inverter dan beban digunakan untuk membebani panel surya sehingga ada arus yang mengalir dari panel surya. Secara garis besar prinsip kerja alat yang dibangun dapat dilihat pada Gambar 1.

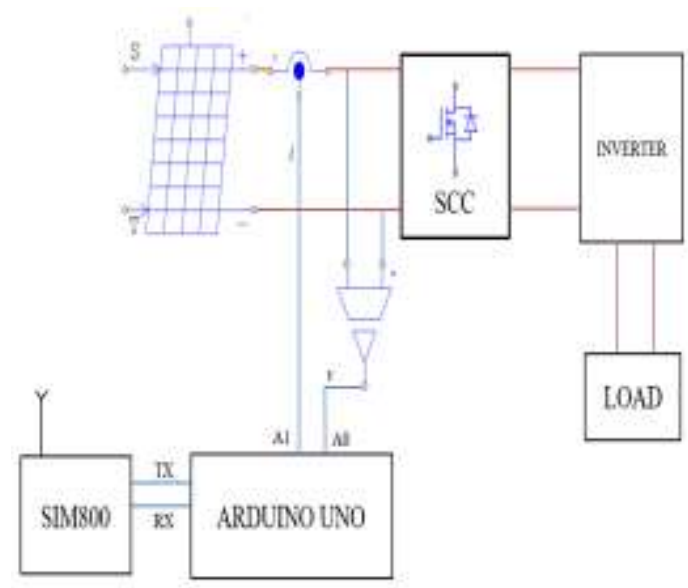

Gambar 1. Diagram kotak sistem data akuisisi dan pemantauan bergerak di lapangan

b. Alir program Sistem data akuisisi dan pemantauan bergerak

Diagram alir sistem Sistem data akuisisi dan pemantauan bergerak yang telah dibangun dapat dilihat pada Gambar 2.

Hal pertama yang dilakukan adalah inisialisasi variabel yang akan menampung hasil pembacaan arus dan tegangan, selanjutnya inisialisasi komunikasi serial anatara Arduino uno dengan modul GSM SIM800L serta pin analog Arduino yang terhubung ke sensor arus dan tegangan. Langkah terakhir adalah mengatur waktu awal. Waktu awal pertama kali diatur bersama dengan menggunakan fungsi millis(). Pada proses selanjutnya dilakukan pengambilan data arus dan tegangan melalui PIN AO dan A1 Arduino, kemudian data tersebut dikirim secara serial ke modem GSM SIM800L. Jika waktu pengiriman sudah lebih dari 45 menit (3240 detik) maka sistem akan berhenti mengukur dan mengirim data hingga selisih antara waktu awal dan millis() lebih besar dari 3600 (1 jam) maka sistem kembali mengirim data seperti proses sebelumnya. Kemudian data juga akan disimpan pada kartu memori yang terhubung dengan Arduino. 


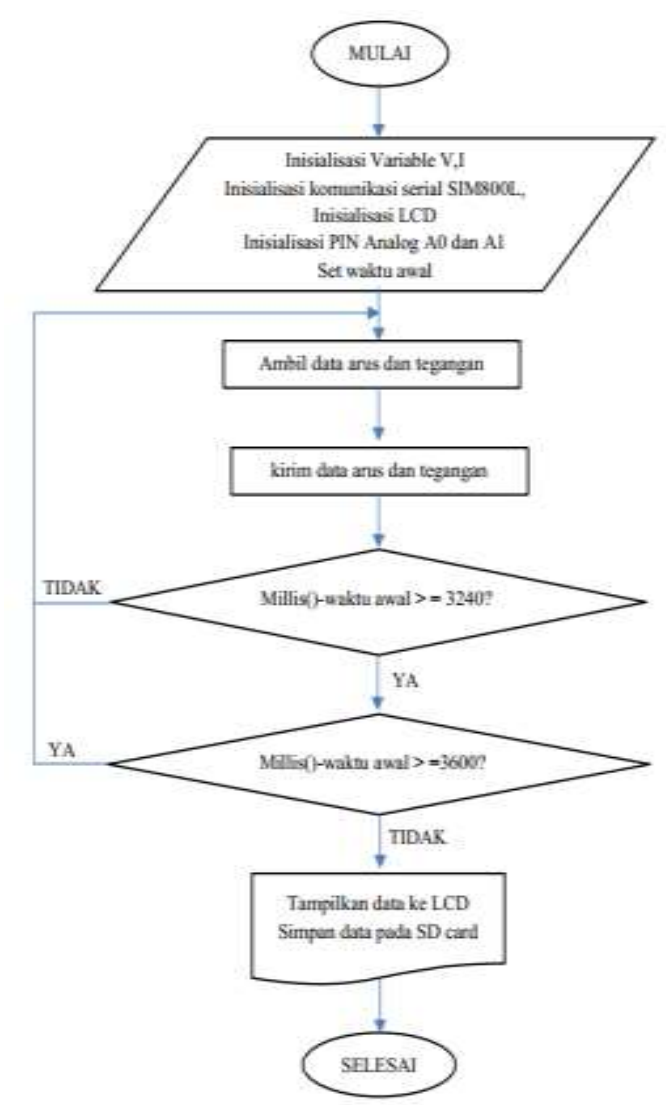

Gambar 2. Diagram Alir program Sistem

c. Perhitungan Panel Generation Factor (PGF) Secara Analitis

Nilai PGF dari masing-masing daerah berbeda-beda tergantung dari tingkat radiasi dan kondisi geografis suatu daerah. Usia panel serta penggunaan Maximum Power Point Tracker (MPPT) juga mempengaruhi nilai PGF. Secara matematis PGF dirumuskan sebagai perkalian antara DF dengan total Horizontal Irradian pada suatu daerah seperti pada persamaan (1).

$$
P G F_{\text {analitis }}=\frac{\overline{G_{T}} \times D F}{\overline{G_{T . S T C}}}
$$

$\overline{G_{T}}$ merupakan total radiasi horizontal perhari

(kWh/m2/hari), sedangkan $\overline{G_{T . S T C}}$ merupakan merupakan radiasi sesaat dalam kondisi standar yaitu sebesar $1 \mathrm{kWh} / \mathrm{m} 2$. DF terdiri atas beberapa komponen diantaranya :

1. suhu permukaan lokasi lebih dari $25^{\circ} \mathrm{C}$, maka terjadi penurunan efisiensi sebesar $15 \%$,
2. adanya penghalang antara sinar matahari mengenai panel, maka terjadi penurunan efisiensi sebesar (5\%),

3. sistem tidak menggunakan MPPT, maka terjadi penurunan efisiensi sebesar (10\%),

4. terdapat debu atau kotoran yang menempel pada permukaan panel maka terjadi penurunan efisiensi sebesar(5\%),

5. faktor usia panel serta penurunan kinerja, maka terjadi penurunan efisiensi sebesar $(10 \%)$

Dari hasil pengamatan di lokasi pengukuran diketahui suhu panel berada diatas 250C, terdapat kerak pada panel yang digunakan, pengukuran tidak menggunakan MPPT, serta usia panel yang digunakan sudah cukup lama sehingga terjadi penurunan kinerja panel. Berdasarkan data tersebut dapat dihitung DF seperti pada persamaan (2).

$$
D F=0,85 \times 0,95 \times 0,9 \times 0,9
$$

Secara ekperimental dengan menggunakan data Global Solar Atlas[10] diperoleh data total radiasi horizontal di Desa Sukosari sebesar 4,849 dengan menggunakan persamaan (1) diperoleh nilai PGF analisis di Desa Sukosari sebesar 3,171.

\section{d. Perhitungan Panel Generation Factor (PGF) secara Eksperimental}

Selain metode analisis dengan menggunakan data yang diperoleh dari data Global Solar Atlas. PGF dapat dihitung secara manual dengan cara membagi jumlah energi rata-rata yang dihasilkan solar panel per hari dengan kapasitas solar panel yang terpasang. Secara matematis dapat ditulis seperti pada parsamaan (3).

$$
P G F_{\text {eksperimental }}=\frac{\text { Totalenergipanelperhari }}{\text { kapasitaspanelterpasang }}
$$

Simpangan nilai antara PGF analisis dengan PGF eksperimental diperoleh dengan menggunakan persamaan (4).

$$
\% \text { simpangan }=\frac{P G F_{\text {eksperimental }}-P G F_{\text {analitis }}}{P G F_{\text {eksperimental }}}
$$

\section{HASIL DAN ANALISIS}

Pengukuran daya yang dilakukan di Desa Sukosari berlangsung selam 3 hari berturutturut dengan spesifikasi peralatan yang digunakan dapat dilihat pada Tabel 1. 
Tabel 1. Bahan penelitian.

\begin{tabular}{cccc}
\hline No & Nama Alat & Kapasitas & Jumlah \\
\hline 1 & Panel surya & $100 \mathrm{Wp}$ & 1 \\
& $\begin{array}{c}\text { polycrystalline } \\
\text { Inverter }\end{array}$ & $500 \mathrm{~W}$ & 1 \\
3 & Beban lampu pijar & $50 \mathrm{~W}$ & 2 \\
4 & Beban lampu pijar & $10 \mathrm{~W}$ & 3 \\
5 & Battery & $15 \mathrm{Ah}$ & 1 \\
6 & Solar Charger & $100 \mathrm{~A}$ & 1 \\
& Controller (SCC) & & \\
\hline
\end{tabular}

Tabel 2. Peralatan yang digunakan dalam pengukuran daya solar panel.

\begin{tabular}{cccc}
\hline No & Nama Alat & Jenis & Jumlah \\
\hline 1 & Multi tester & $\begin{array}{c}\text { Digital, } \\
\text { merk Fluke }\end{array}$ & 2 \\
2 & $\begin{array}{c}\text { Perangkat Data } \\
\text { Akuisisi }\end{array}$ & 1 \\
\hline
\end{tabular}

Pengukuran dilakukan dengan meletakkan panel pada lokasi yang memungkinkan panel terpapar sinar matahari secara langsung untuk mengurangi nilai Derating Factor (DF). Proses pemasangan dan pengaturan perangkat dapat dilihat pada Gambar 4.

Tegangan dalam Volt, A adalah nilai Arus dalam Ampere, LX merupakan intesnsitas cahaya dalam LUX, dan DL merupakan urutan data dalam data logger. Kegiatan pengujian dan setting perangkat dilaksanakan pada lingkungan yang relatif teduh sehingga data arus yang dibangkitkan oleh solar panel sangat kecil (kurang dari 0,5 A). Pengujuan dilakukan selama tiga hari berturut-turut. Modul GSM mengirimkan data Tegangan, Arus dan Daya yang dikonsumsi melalui SMS seperti yang ditunjukkan pada Gambar 5. Setelah melaksanakan kegiatan pengukuran selama 3 hari berturut-turut diperoleh data hasil pengukuran seperti pada Tabel 3.

Pada tahap ini hal yang dilakukan adalah menguji fungsi sensor serta pengujian komunikasi wireless GSM. Hasil pengujian komunikasi wireless GSM dapat dilihat pada Gambar 3.

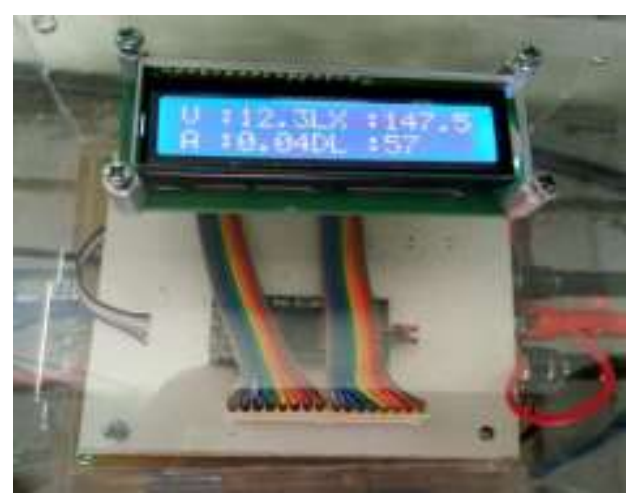

Gambar 3. Sistem data akuisisi

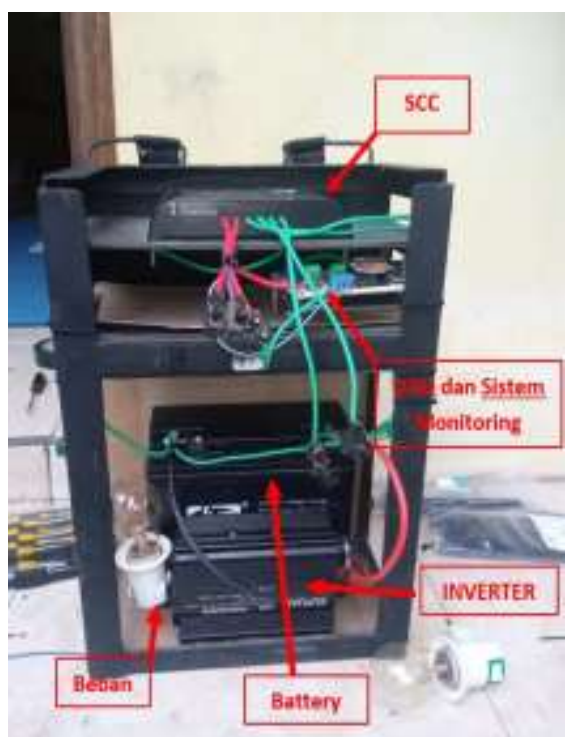

Gambar 4. Susunan perangkat sistem data akusisi dan pemantauan bergerak yang terpasang di lapangan

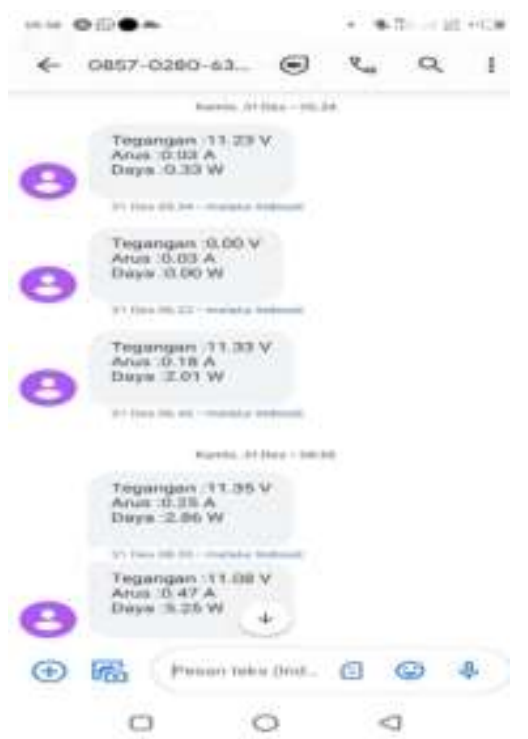

Gambar 5. Format pengiriman data secara Wireless dengan menggunakan modul GSM 
Tabel 3. Hasil Pengukuran Energi yang Dibangkitkan oleh Panel Surya. Lokasi: Desa Sukosari

\begin{tabular}{|c|c|c|c|c|c|c|c|}
\hline $\begin{array}{c}\text { Hari } \\
\text { ke- }\end{array}$ & Interval & $\begin{array}{l}\text { Waktu } \\
\text { (Jam) }\end{array}$ & $\begin{array}{c}\text { Tegangan } \\
\text { (V) }\end{array}$ & $\begin{array}{l}\text { Arus } \\
\text { (A) }\end{array}$ & $\begin{array}{c}\text { Daya } \\
\text { (W) }\end{array}$ & $\begin{array}{c}\text { Energy } \\
\text { (Wh) }\end{array}$ & $\begin{array}{l}\text { Energi total } \\
\text { (Wh) }\end{array}$ \\
\hline \multirow{11}{*}{1} & 07:00 & 0.75 & \multirow{2}{*}{10,53} & \multirow{2}{*}{2,52} & \multirow{2}{*}{26,55} & 19,9096 & \multirow{11}{*}{316,1093} \\
\hline & 08:00 & 0.75 & & & & 24,33753 & \\
\hline & 09:00 & 0.75 & 10,74 & 3,65 & 39,20 & 29,40075 & \\
\hline & $10: 00$ & 0.75 & 13,50 & \multirow{2}{*}{4,11} & \multirow{2}{*}{55,44} & 41,58338 & \\
\hline & $11: 00$ & 0.75 & \multirow{2}{*}{11,40} & & & 38,4408 & \\
\hline & $12: 00$ & 0.75 & & 4,50 & 51,25 & 46.7775 & \\
\hline & $12 \cdot 00$ & 075 & 13,20 & \multirow{2}{*}{4,30} & \multirow[b]{2}{*}{58,05} & (2) & \\
\hline & 13.00 & 0.15 & 13,50 & & & $43,53 / 5$ & \\
\hline & $14: 00$ & 0.75 & 12,90 & 4,20 & 54,18 & 40,635 & \\
\hline & $15: 00$ & 0.75 & 13,50 & 2,01 & \multirow{2}{*}{27,14} & 20,35125 & \\
\hline & $16: 00$ & 0.75 & 11,60 & 1,25 & & 11,136 & \\
\hline \multirow{11}{*}{2} & $07: 00$ & 0.75 & 10,49 & \multirow{2}{*}{2,52} & \multirow{2}{*}{26,45} & 19,83397 & \\
\hline & 08:00 & 0.75 & 10,65 & & & 23,43533 & \\
\hline & 09:00 & 0.75 & 11,32 & 3.65 & 41.32 & 30,9885 & \\
\hline & $10: 00$ & 0.75 & 13,13 & 4.11 & 53.92 & 40,44368 & \\
\hline & 11:00 & 0.75 & 1240 & 4.50 & 5575 & 41,8128 & \\
\hline & $12: 00$ & 0.75 & 12,40 & 4,00 & (3) & 47,73938 & 317,2033 \\
\hline & 13:00 & 0.75 & 10,50 & 4,12 & 03,05 & 43,09988 & \\
\hline & $14: 00$ & 0.75 & 13,65 & 4,21 & 57,47 & 40,131 & \\
\hline & 15:00 & 0.75 & 12,14 & $4, \angle \mathrm{U}$ & 30,01 & 18,84375 & \\
\hline & $16: 00$ & 0.75 & 12,50 & 2,01 & 25,13 & 10,875 & \\
\hline & & & 11,60 & 1,25 & 14,50 & & \\
\hline & 07:00 & 0.75 & 10,92 & 2,52 & 27,53 & 20,64699 & \\
\hline & 08:00 & 0.75 & 11,16 & 2,93 & 32,74 & 24,55758 & \\
\hline & 09:00 & 0.75 & 12,74 & 3,65 & 46,50 & 34,87575 & \\
\hline & $10: 00$ & 0.75 & 13,50 & 4,11 & 55,44 & 41,58338 & \\
\hline & $11: 00$ & 0.75 & 13,40 & 4,50 & 60,25 & 45,1848 & \\
\hline 3 & $12: 00$ & 0.75 & 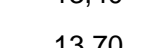 & 455 & 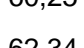 & 46,75125 & 325,7664 \\
\hline & 13:00 & 0.75 & (1), & 4,0 & $0<, 04$ & 41,62388 & \\
\hline & $14: 00$ & 0.75 & 13,50 & 4,11 & 55,50 & 40.635 & \\
\hline & $15: 00$ & 075 & 12,90 & 4,20 & 54,18 & & \\
\hline & & 0.75 & 12,51 & 2,01 & 25,15 & 18,85883 & \\
\hline & $16: 00$ & 0.75 & 11,60 & 1,25 & 14,50 & 11,049 & \\
\hline & & & otal Energi Se & 3 Hari & & & 958,917 \\
\hline & & & Rata-Rata Ene & r Hari & & & 319,639 \\
\hline
\end{tabular}


Berdasarkan data tersebut dapat dihitung nilai dari $P F_{\text {eksperimental dengan }}$ mensubtitusikan nilai daya rata-rata yang diperoleh ke persamaan (3) dengan hasil 3,1971 . Sedangkan prosentasi error antara $\mathrm{PGF}_{\text {Analitis }}$ dan $\mathrm{PGF}_{\text {eksperimental }}$ diperoleh dengan menggunakan persamaan (4) diperoleh nilai simpangan sebesar $0,81 \%$.

\section{KESIMPULAN}

Panel Generation Factor (PGF) merupakan besaran yang sangat penting dalam perancangan sistem pembangkit tenaga surya secara optimal dan efisien. Berdasarkan hasil pengujian dan pengukuran yang dilaksanakan di Desa Sukosari, Kabupaten Magelang, Jawa Tengah, diperoleh hasil $\mathrm{PGF}_{\text {analitis }}$ sebesar 3,171 serta PGF $_{\text {eksperimental sebesar 3,1971. Dari data }}$ tersebut diperoleh nilai simpangan sebesar $0,81 \%$ anatara nilai analitis dan nilai eksperimental. Hal tersebut menunjukkan bahwa nilai $\mathrm{PGF}_{\text {eksperimental memiliki }}$ keakurasian yang lebih baik dibandingkan dengan nilai $\mathrm{PGM}_{\text {analitis. }}$ Sistem data akuisisi mobile yang dibuat menunjukkan bahwa keakuratan serta fungsi yang baik terlihat dari rendahnya nilai simpangan antara data hasil analisis dengan data hasil eksperimental.

\section{REFERENSI}

[1] Anonim, "Kebijakan Nasional Energi Baru Terbarukan dan Konservasi Energi. Kementerian Energi dan Sumber Daya Mineral," Direktorat Jenderal Energi Baru Terbarukan dan Konservasi Energi, 2019.

[2] A. Hidayatullah, A. Maruf, D. A. Islachulchoir, D. P. Pibadi, dan Y. Rahmawati, "Sistem Pembangkit Energi Surya Pada Penerangan Jalan Umum Tenaga Surya Di Lingkungan Fakultas Teknik Universitas Negeri Malang," Indones. J. Electr. Electron. Eng., vol. 02 No. 02, pp. 34-39, 2019.

[3] S. Aryza, H. Hermansyah, A. P. U. Siahaan, Suherman, dan L. Zulkarnain "Implementasi Energi Surya Sebagai Sumber Suplai Alat Pengering Pupuk Petani Portabel," IT J. Res. , 2017, [Online]. Available: https://journal.uir.ac.id/ index.php/ITJRD/article/view/642.

[4] A. D. Lesmana, O. R. M. Hartman, A. Wahyuningtyas, dan I. Irzaman, "Tedapis (Tenda Darurat Pintar Bertenaga Panel Surya) Sebagai Solusi Penyediaan Energi Listrik Bagi Korban Bencana Alam," vol. VIII, pp. SNF2019-PA-107-114, 2019, doi: 10.21009/03.snf2019.02.pa.15.

[5] M. R. Vegatama, K. Willard, R. H. Saputra, A. Sahara, dan M. A. Ramadhan., "Rancang Bangun Filter Air Dengan Filtrasi," vol. 2, pp. 1-10, 2020.
[6] M. EL-Shimy, "Daily solar irradiance for a given month based on monthly average hourly radiations," pp. 4-5, 2017.

[7] E. A. Benjamin and E. Dickson, "Estimating the Solar Home System Sizing for Rural Residential Apartments Using a Panel Tilt Angle of 82 Degrees :

90-96, 2017, doi: 10.11648/j.ece.20170103.13

[8] T. Khatib, I. A. Ibrahim, and A. Mohamed, "A review on sizing methodologies of photovoltaic array and storage battery in a standalone photovoltaic system," Energy Convers. Manag., vol. 120, no. September 2018, pp. 430-448, 2016, doi: 10.1016/j.enconman.2016.05.011.

[9] J. A. Onwuzuruike and M. A. Aminu, "Experimental Determination of Panel Generation Factor for Apo Area of Federal Capital Territory in Nigeria," J. Sci. Res. Reports, vol. 24, no. 3, pp. 1-5, 2019, doi: 10.9734/jsrr/2019/v24i330157.

[10] Anonim, "Global Solar Atlas." https:// globalsolaratlas.info/ map? $\mathrm{C}=-7.518498$, $110.129356,12 \& \mathrm{~s}=-7.470163,110.179825 \&$ $\mathrm{m}=$ site (accessed Jan 26, 2021). 